REFERENCES:

[1] Smolen JS, et al. Ann Rheum Dis 2017;76:960-977.

[2] Smolen JS, Landewé R, Bijlsma J, et al. EULAR recommendations for the management of rheumatoid arthritis with synthetic and biological diseasemodifying antirheumatic drugs: 2016 update. Ann Rheum Dis 2017;76:960-977.

Acknowledgements: RABBIT is supported by a joint, unconditional grant from AbbVie, Bristol-Myers Squibb, Celltrion, Hexal, Lilly, MSD Sharp and Dohme, Pfizer, Roche, Samsung Bioepis, Sanofi und UCB.

Disclosure of Interest: L. Baganz: None declared, A. Richter: None declared, K. Albrecht: None declared, M. Schneider Grant/research support from: Abbvie, Chugai, UCB, Consultant for: Abbvie, Astra-Zeneca, BMS, Chugai, GSK, Lilly, MSD, Mundipharma, Pfizer, Roche, UCB, G.-R. Burmester Consultant for: AbbVie, BMS, Lilly, MSD, Pfizer, Roche, UCB, A. Zink Speakers bureau: BMS, Lilly, Pfizer, Roche, UCB, A. Strangfeld Speakers bureau: AbbVie, BMS, Lilly, MSD, Pfizer, Roche, UCB

DOI: 10.1136/annrheumdis-2018-eular.4564

\section{OP0214 BASELINE COMORBIDITIES AND OVERWEIGHT PREDICT FUNCTIONAL STATUS AND HEALTH- RELATED QUALITY OF LIFE 9 YEARS LATER - A LONGITUDINAL COHORT STUDY OF 428 PATIENTS WITH RHEUMATOID ARTHRITISRECEIVING STANDARD CARE}

L. Linde ${ }^{1}$, M.L. Hetland ${ }^{2} .{ }^{1}$ Center for Rheumatology and Spine Diseases; ${ }^{2}$ DANBIO, Center for Rheumatology and Spine Diseases, Rigshospitalet, Copenhagen, Denmark

Background: Health-related quality of life (HRQOL) and functional status are markedly reduced in patients with rheumatoid arthritis (RA) leading to a significant societal and individual burden. Comorbidities and sociodemographic factors are associated with reduced HRQOL and functional status in cross-sectional studies of RA, ${ }^{1}$ but their predictive value is largely unknown as longitudinal studies are lacking.

Objectives: To investigate whether comorbidities and sociodemographic factors predict $\mathrm{HRQOL}$ and functional status 9 years later in real-world patients with RA.

Methods: Consecutive patients with RA were recruited from a university hospital outpatient clinic between ${ }^{\text {Juy } 2006}$ and July 2007. Data regarding sex, age, disease duration, disease activity score of 28 joints and CRP (DAS28), number of comorbid conditions, marital status (married/cohabiting vs living alone), smoking (ever, previously or currently), exercise ( $\geq$ once a week vs not regularly), body mass index (BMI), educational level (elementary, training or higher), functional status (the health assessment questionnaire (HAQ)) and HRQOL (Euroqol 5 dimensions (EQ-5D)) were registered in the clinical database DANBIO; patients then continued routine care.

EQ-5D includes 5 dimensions of health (mobility, self-care, usual activities, pain/ discomfort, anxiety/depression), each divided into three levels of severity, yielding 243 possible health states. A validated algorithm converts each health state into an index score between 0 (death) and 1 (perfect health). ${ }^{2}$

$\mathrm{HAQ}$ and EQ-5D scores at the most recent follow-up visit were retrieved from DANBIO on Sept 30th 2017. Two linear regression models were built with scores for $\mathrm{HAQ}$ and $\mathrm{EQ}-5 \mathrm{D}$ at follow-up as outcomes, respectively, all baseline variables were entered as possible explanatory variables and stepwise backward selection was employed. Sex, age, disease duration and baseline HAQ/EQ-5D were forced into the models.

Results: 564 patients with RA were recruited ( $81 \%$ women, median (IQR) age: $60^{49-68}$ years, disease duration: 7 (3-16) years, DAS28: 2.9 (2.1-3.7), HAQ: 0.63 (0.25-1.25), EQ-5D: $0.74(0.66-0.82)$ and followed in routine care for a median of $9^{4-10}$ years. 428 and 256 patients had complete $\mathrm{HAQ}$ and EQ-5D scores, respectively at follow-up (HAQ: $0.75(0.25-1.4)$, EQ-5D: $0.78(0.69-0.86)$ ). Patients without complete $\mathrm{HAQ}$ and $\mathrm{EQ}-5 \mathrm{D}$ scores at follow-up were older at baseline (10 and 6 years, respectively, $p<0.0001$ ), while sex, disease duration, DAS28, HAQ and EQ-5D scores were similar.

High HAQ, BMI $26-30 \mathrm{~kg} / \mathrm{m} 2$, and 3 or more comorbid conditions at inclusion were all independently associated with poorer functional status and low EQ-5D 9 years later (table 1). The models with $\mathrm{HAQ}$ or EQ-5D as outcome explained $51 \%$ and $31 \%$ of the variation $\left(\operatorname{Adj} R^{2}\right.$ ), respectively.
Abstract OP0214 - Table 1 Multivariable linear regression model with $\mathrm{HAQ}$ and EQ-5D at follow-up as outcomes.

\begin{tabular}{|c|c|c|c|c|c|c|}
\hline \multirow{3}{*}{$\begin{array}{l}\text { Explanatory variables } \\
\text { Women }\end{array}$} & \multicolumn{3}{|c|}{ HAQ at follow up } & \multicolumn{3}{|c|}{ EQ-5D at follow up } \\
\hline & Coefficient & $95^{\circ}$ & & Coefficient & $95 \%$ & $\mathrm{CI}$ \\
\hline & 0.19 & 0.06 & 0.33 & -0.03 & -0.08 & 0.02 \\
\hline Age (50-75 yrs) & 0.06 & -0.05 & 0.18 & 0.03 & -0.01 & 0.07 \\
\hline $\operatorname{Age}(>75$ yxs $)$ & 0.03 & -0.22 & 0.28 & 0.01 & -0.10 & 0.11 \\
\hline Disease duration (3-10 yrs) & 0.10 & -0.03 & 0.23 & -0.01 & -0.06 & 0.04 \\
\hline Disease duration (>10 yxs) & 0.12 & -0.02 & 0.25 & -0.02 & -0.07 & 0.03 \\
\hline Baseline HAQ (per unit increase) & 0.72 & 0.63 & 0.81 & -0.10 & -0.14 & -0.05 \\
\hline Baseline EQ-5D (per unit increase) & NS & - & - & 0.13 & -0.05 & 0.30 \\
\hline $\operatorname{BMI}\left(<18,5 \mathrm{~kg} / \mathrm{m}^{2}\right)$ & 0.27 & -0.08 & 0.62 & -0.09 & -0.23 & 0.04 \\
\hline BMI $\left(26-30 \mathrm{~kg} / \mathrm{m}^{2}\right)$ & 0.22 & 0.10 & 0.33 & -0.09 & -0.13 & -0.04 \\
\hline $\mathrm{BMI}\left(>30 \mathrm{~kg} / \mathrm{m}^{2}\right)$ & 0.16 & 0.01 & 0.32 & -0.03 & -0.08 & 0.03 \\
\hline One comorbid condition & 0.13 & 0.01 & 0.26 & -0.02 & -0.07 & 0.02 \\
\hline Two comorbid conditions & -0.03 & -0.18 & 0.12 & 0.03 & -0.03 & 0.08 \\
\hline$\geq 3$ comorbid conditions & 0.30 & 0.14 & 0.47 & -0.14 & -0.20 & -0.08 \\
\hline Constant & 0.39 & 0.07 & 0.72 & 0.79 & 0.64 & 0.94 \\
\hline
\end{tabular}

Conclusions: Potentially modifiable factors (overweight and comorbidities) were independently and consistently associated with worse functional status and HRQOL at follow-up 9 years later in patients with RA receiving standard care. The findings suggest that focus on lifestyle and comorbidities in patients with RA may improve important long-term outcomes.

REFERENCES:

[1] Linde L, et al. J Rheumatol 2009;36(10):2183-2189.

[2] Wittrup-Jensen K, et al. Scand J Public Health 2009;00:1-8.

Disclosure of Interest: None declared

DOI: 10.1136/annrheumdis-2018-eular.2098

THURSDAY, 14 JUNE 2018

Musculoskeletal pain; feeding the opioid epidemic_

\section{OP0215 TIME-RELATED TRENDS IN OPIOID PURCHASES AMONG PATIENTS WITH EARLY INFLAMMATORY ARTHRITIDES}

P. Muilu ${ }^{1}$, V. Rantalaiho ${ }^{2,3}$, H. Kautiainen ${ }^{4}$, L.J. Virta ${ }^{5}$, K. Puolakka ${ }^{6} .{ }^{1}$ Department of Medicine, Tampere University Hospital; ${ }^{2}$ Centre fo rheumatic diseases, Tampere University Hospital; ${ }^{3}$ Faculty of Medicine and Life sciences, University of Tampere, Tampere; ${ }^{4}$ Department of General Practice and Primary Health Care, University of Helsinki and Helsinki University Hospital, helsinki; ${ }^{5}$ Research Department, Social Insurance Institution of Finland, Turku; ${ }^{6}$ Department of Medicine, South Karelia Central Hospital, Lappeenranta, Finland

Background: Treatment outcomes in inflammatory arthritis (IA) have improved during the past decades; however, pain management remains a great challenge. There has been a concern of overprescription of opioids during recent years.

Objectives: The aim of this study was to explore the frequency of opioid users in patients with newly-onset IA in comparison with the general Finnish population and discover the proportion of long-term opioid users.

Methods: From the nationwide register maintained by the Social Insurance Institution of Finland we collected all incident adult patients with the five most common IAs between 2010-14. For each case, three eligible controls were randomly selected and individually matched according to age, sex, and place of residence. Opioid purchases between 2009-2015 were obtained from the drug prescription register and evaluated one year before and after the index date (decision of special reimbursement for antirheumatic drugs), further dividing the observation time into 3 month periods. Long-term use was defined as opioid purchases at least in three of these periods per year. All opioids from mild to strong were included.

Results: Data on different diagnosis groups are presented in table 1. The proportion of opioid purchasers among IA patients and their controls are shown in figure $1 \mathrm{~A}-\mathrm{E}$. Also, odds ratio for long-term opioid use after the index date is shown in figure $1 \mathrm{~F}$. 
Abstract OP0215 - Table 1. Number (N), proportion of females (\%), and mean ages at baseline of incident patients with inflammatory arthritides between 2010 and 2014 in Finland.

\begin{tabular}{lccccc}
\hline & RA+ & RA- & UA & SpA & PsA \\
& $\mathbf{n}=\mathbf{6 1 8 6}$ & $\mathbf{n = 2 9 7 0}$ & $\mathbf{n = 2 9 5 9}$ & $\mathbf{n = 3 5 7 7}$ & $\mathbf{n = 2 6 7 0}$ \\
\hline Age, mean (SD) & $58(15)$ & $57(17)$ & $49(17)$ & $38(12)$ & $49(13)$ \\
$\begin{array}{l}\text { Proportion of females } \\
\text { (\%) }\end{array}$ & 66.4 & 67.2 & 67.4 & 52.3 & 48.8 \\
\hline
\end{tabular}

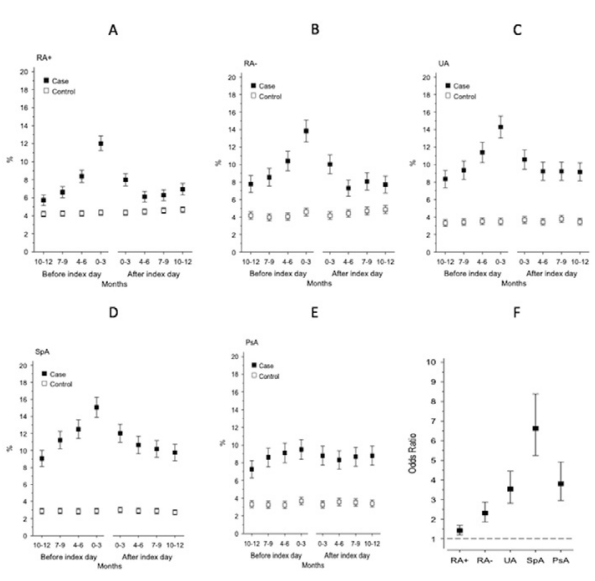

Abstract OP0215 - Figure 1. Proportion of opioid purchasers among patients with incident A) seropositive rheumatoid arthritis (RA+), B) seronegative rheumatoid arthritis (RA-), C) unspecified arthritis (UA), D) spondyloarthritis [(SpA), including ankylosing spondylitis and non-radiographic axial spondyloarthritis], and E) psoriatic arthritis (PsA) and their controls one year before and after the index date. F) Odds ratio for long-term opioid use among incident RA+, RA-, UA, SpA, and PsA patients versus controls after the index date.

Conclusions: IA patients are more likely to buy opioids one year before and one year after the diagnosis and presciption of antirheumatic medication than controls from the general population. The opioid purchases peak just before the index date in most IA patients. Long-term opioid use is also more common among patients with newly-onset IA, especially among those with SpA.

Disclosure of Interest: P. Muilu Grant/research support from: Competitive State Research Financing of the Expert Responsibility Area of Tampere University Hospital, Rheumatology Research Foundation, and Finnish Cultural Foundation., V. Rantalaiho Grant/research support from: Competitive State Research Financing of the Expert Responsibility Area of Tampere University Hospital, and Tampereen Reumayhdistys, H. Kautiainen: None declared, L. Virta: None declared, K. Puolakka: None declared

DOI: 10.1136/annrheumdis-2018-eular.4270

\section{OP0216 EXAMINING MODIFIABLE PSYCHOLOGICAL \& SOCIAL HEALTH FACTORS ASSOCIATED WITH USE OF OSTEOARTHRITIS ORAL ANALGESIC TREATMENT}

E.R. Vina ${ }^{1}$, L. Hausmann ${ }^{2}$, D.S. Obrosky ${ }^{2}$, A. Youk ${ }^{2}$, D. Weiner ${ }^{3}$, S. Ibrahim ${ }^{4}$, C. K. Kwoh ${ }^{1}$. ${ }^{1}$ Medicine, University of Arizona, Tucson; ${ }^{2} \mathrm{CHERP} ;{ }^{3}$ Geriatric, VAPHS, Pittsburgh; ${ }^{4}$ CHERP, Philadelphia VAMC, Philadelphia, USA

Background: EULAR recommends the use of non-opioid oral medicines (acetaminophen, NSAIDs, or COX-2 inhibitors) for the management of knee osteoarthritis $(\mathrm{OA})$. Opioids are also recommended when these other therapies fail. There are known demographic and clinical differences in OA treatment use. Patients' social and psychological health may also influence use of medications, yet their association with the utilisation of opioid or non-opioid oral OA treatments is unknown.

Objectives: Determine which modifiable social and psychological health factors are associated with use of oral opioid and non-opioid medications for OA.

Methods: Baseline data from a randomised controlled trial that examined the effects of a positive psychological intervention on pain in veterans with knee $O A$ were used. For our study, patients were categorised based on self-reported use of the following oral medications for OA at baseline: opioids (with/without other oral analgesic treatments), non-opioid analgesics, and no oral analgesic treatment. We used $\chi^{2}$ or analysis of variance to compare sociodemographic, clinical, social, and psychological health variables by baseline OA treatment use. We used multinomial logistic regression models to estimate adjusted relative risk ratios (RRRs) of using an opioid or a non-opioid analgesic (vs. no oral analgesic treatment), comparing patients by levels of social support (Medical Outcomes Study), health literacy ('How confident are you filling out medical forms by yourself'), and depressive symptoms (Patient Health Questionnaire-8). All models were adjusted for age, sex, race, income, OA symptom severity (WOMAC), self-reported Charlson comorbidity index, and body mass index.

Results: In this sample, $30.6 \%(n=110)$ reported taking opioid analgesics for OA $54.2 \%(n=195)$ reported non-opioid use, and $15.3 \%(n=55)$ reported no oral analgesic use. Compared to the other groups, those taking opioids were younge (mean age 62.5 vs 64.3 vs 67.1 , respectively, $p=0.002$ ) and had higher mean WOMAC scores (54.5 vs 45.7 vs $42.7, \mathrm{p}<0.001$ ). Opioid users also had lowe mean social support scores ( 10.0 vs 10.5 vs $11.9, \mathrm{p}=0.007$ ) and were more likely to have moderate-severe depression $(42.7 \%$ vs $24.1 \%$ vs $14.5 \%, p<0.001)$. Hav ing adequate health literacy did not differ by treatment group type.

Abstract OP0216 - Table 1 Social and psychological variables associated with oral analgesic treatment use*

\begin{tabular}{|c|c|c|c|}
\hline & $\begin{array}{l}\text { Adjusted relative } \\
\text { risk ratio }\end{array}$ & $95 \% \mathrm{Cl}$ & p-value \\
\hline \multicolumn{4}{|l|}{ Non-Opioid Oral Analgesic Use † } \\
\hline Social support & 0.94 & $(0.86,1.03)$ & 0.188 \\
\hline Adequate health literacy & 0.52 & $(0.21,1.30)$ & 0.160 \\
\hline Depression, moderate to severe & 1.93 & $(0.72,5.12)$ & 0.189 \\
\hline \multicolumn{4}{|l|}{ Opioid Use † } \\
\hline Social support & 0.92 & $(0.83,1.02)$ & 0.120 \\
\hline Adequate health literacy & 0.53 & $(0.20,1.42)$ & 0.207 \\
\hline Depression, moderate to severe & 2.96 & $(1.08,8.07)$ & 0.035 \\
\hline \multicolumn{4}{|l|}{ Opioid Use $\mp$} \\
\hline Social support & 0.98 & $(0.92,1.05)$ & 0.601 \\
\hline Adequate health literacy & 1.02 & $(0.55,1.89)$ & 0.954 \\
\hline Depression, moderate to severe & 1.53 & $(0.87,2.71)$ & 0.140 \\
\hline
\end{tabular}

The table 1 shows the associations between the social and psychological health measures with oral analgesic use, adjusted for sociodemographic and clinical factors. Having moderate-severe depression was associated with higher risk of opioid analgesic use compared to no oral analgesic use (RRR 2.96, 95\% Cl: 1.08 to 8.07) when adjusted for sociodemographic and clinical factors. Depression level was not significantly associated with non-opioid oral medication use, compared to no oral analgesic medication use, in a similarly adjusted model. Neither social support nor health literacy was associated with opioid or non-opioid ora analgesic use in fully adjusted models.

Conclusions: Knee OA patients with more severe depression symptoms, com pared to those without, were more likely to report using opioid (vs. non-opioid) analgesics for OA. Social support and health literacy were not significantly associated with oral analgesic use for OA when sociodemographic and clinical factors were accounted for

Disclosure of Interest: E. Vina: None declared, L. Hausmann: None declared, D. Obrosky: None declared, A. Youk: None declared, D. Weiner: None declared, S. Ibrahim: None declared, C. Kwoh Grant/research support from: Abbvie, EMD Serono, Consultant for: Astellas, EMD Serono, Thusane, Express Scripts, Novartis

DOI: 10.1136/annrheumdis-2018-eular.3813

\section{THURSDAY, 14 JUNE 2018}

\section{What is lupus - syndrome or different entities?}

\section{OP0217 A PERMEABLE BLOOD-BRAIN BARRIER IS NOT REQUIRED FOR NEUROPSYCHATRIC MANIFESTATIONS IN SLE AND PSS}

M.B. Lauvsnes ${ }^{1}$, A.B. Tjensvoll ${ }^{2}$, S.S. Maroni ${ }^{3}$, I. Kvivik ${ }^{1}$, T.B. Grimstad ${ }^{1}$, O. J. Greve ${ }^{4}$, E. Harboe ${ }^{1}$, L.G. Gøransson ${ }^{1}$, C. Putterman ${ }^{5}$, R. Omdal' ${ }^{1}{ }^{1}$ Medical Department, ${ }^{2}$ Neurology, ${ }^{3}$ Psychiatry, ${ }^{4}$ Radiology, Stavanger University Hospital, Stavanger, Norway; ${ }^{5}$ Division of Rheumatology, Albert Einstein College of Medicine, New York, USA

Background: A prevailing hypothesis for neuropsychiatric (NP) manifestations in systemic lupus erythematosus (SLE) and primary Sjögren's syndrome (pSS) is that brain reactive autoantibodies can enter the brain through an impaired bloodbrain barrier (BBB) during inflammatory conditions. Based on murine models the cytokine TWEAK could contribute to NP phenomena by binding Fn14 on brain endothelial cells. This will open the BBB and allow brain-reactive autoantibodies produced in the periphery to reach their targets in the brain.

Objectives: The aim of this study was to investigate the role of the BBB's permeability for NP manifestations in human SLE and pSS. Also, we wished to investigate whether increased TWEAK concentrations could be attributed to brain 